\title{
Potencialidades da construção de Programas de Estimulação na formação de Educadores Sociais
}

\author{
Susana Fonseca*, Lia Araújo *, Maria João Amante *, Ana Raquel Rodrigues**, Diana Vieira**, Helena Marques** \\ * Escola Superior de Educação de Viseu e CI\&DETS, IPV, ** Escola Superior de Educação Viseu, IPV
}

\begin{abstract}
Resumo
Este estudo analisa uma experiência de formação, na qual um grupo de 11 estudantes foi acompanhado durante o processo de planeamento, desenvolvimento e avaliação de um programa de estimulação multissensorial e reminiscências para pessoas idosas. O programa foi constituído por 12 sessões, desenvolvidas uma vez por semana $(n=8)$ e duas vezes por semana $(n=2 \times 8)$. Após o desenvolvimento do programa, os alunos foram convidados a participar num focus group, cujas principais contribuições apontaram para a importância de existir um programa estruturado, com todas as sessões previamente preparadas pelos próprios estudantes e ainda para alguns aspetos relacionados com a operacionalização do programa.

Palavras-chave: estimulação multisensorial, reminiscencias, pessoas idosas, intervenção socioeducativa
\end{abstract}

O fenómeno de envelhecimento populacional tem introduzido desafios significativos, que devem ser contemplados na formação de educadores, visto que as pessoas idosas vão passar a constituir um grupo-alvo de intervenção socioeducativa cada vez mais comum. Intervenções promissoras nas quais a reminiscência é combinada com outras abordagens, tais como a estimulação cognitiva e sensorial, são muito recentes e já demonstraram ter um impacto positivo nas pessoas com idade avançada, particularmente na promoção do seu bem-estar psicológico (Bohlmeijer, Roemer, Cuijpers, \& Smit, 2007).

A estimulação multisensorial é importante para o bem-estar e qualidade de vida, sendo considerada uma estratégia de suporte emocional e afetivo e de respeito, que contribui para reduzir a agitação e os distúrbios de sono (Victorian Government, 2010). Baseia-se na estimulação dos sentidos primários (olfacto, tacto, visão, audição e gosto), sem necessidade de recorrer a processos cognitivos complexos (Baillon, van Diepen, \& Prettyman, 2002). A reminiscência consiste na recordação de uma experiência ou facto, à qual o sujeito associa de modo habitual dor ou prazer (Afonso, 2012). Numa perspectiva de intervenção, a terapia de reminiscência pode ser utilizada para promover a autoestima, aumentar o bem-estar e prevenir o aparecimento de sintomatologia depressiva (Bohlmeijer et al., 2007).

O envelhecimento pode ser definido como um período do ciclo de vida em que existe uma mudança das características pessoais, ao nível biológico, psicológico e social, associadas a uma perda gradual da capacidade de adaptação. Considerando os vários problemas e fragilidades do envelhecimento, a intervenção com pessoas idosas deve procurar ser estruturada e orientar-se sobretudo para os aspetos de funcionamento positivo. É, por isso, "necessário encontrar respostas científicas que expliquem o envelhecimento humano e fazer a sua translação para a prática através da criação de serviços inovadores para uma sociedade inclusiva e solidária, onde o envelhecimento não seja visto como um problema, mas uma conquista produtiva do ser humano" (Paúl \& Ribeiro, 2012, p. XIX). Assim, é importante que os estudantes de Educação Social estejam preparados para intervir nesta área, apreendendo as principais características do processo de envelhecimento, desenvolvendo competências de construção de ferramentas e estratégias para intervir com esta população.

O presente estudo objetiva reportar os resultados de uma experiência de formação, na qual um programa de estimulação multisensorial e de reminiscências para pessoas idosas foi construído e implementado por um grupo de alunos da licenciatura em Educação Social da Escola Superior de Educação de Viseu.

\section{Método}

El primer nivel de título irá centrado, en negrita y con únicamente la primera letra en mayúscula. El espaciado anterior será de 10 puntos y el posterior de 3. La fuente será la misma que para el resto del texto. Se tendrá la precaución de no dejar un título sin texto debajo al final de una página o columna. Los títulos de primer nivel serán: Método, Resultados, Discusión y Referencias.

\section{Descrição do programa}

O programa de estimulação multissensorial e de reminiscências para pessoas idosas foi desenvolvido por um grupo de 9 estudantes estagiários do curso de Licenciatura em Educação Social, tendo sido acompanhado durante todo o processo de planeamento, desenvolvimento e avaliação por uma equipa de 3 docentes.

O programa foi constituído por 12 sessões, de 45 minutos cada, organizadas em três fases, estruturadas da seguinte forma:

(i) fase inicial - são dadas as boas vindas de forma individual e utilizado o nome dos participantes; recorda-se o nome do grupo e canta-se a música associada ao mesmo, sendo que tanto o nome, como a música são definidos em conjunto na primeira sessão; 
são questionados aspetos relativos à orientação temporal (ex.: dia da semana, dia do mês e ano, estação do ano e estado do tempo) e à orientação espacial (ex.: nome e morada do local onde se encontram); partilham-se e discutem-se acontecimentos recentes (por exemplo, notícias que tenham lido em jornais e/ou revistas, ouvido na televisão e/ou rádio ou mesmo acontecimentos recentes ocorridos no local onde está a ser aplicado o programa).

(ii) fase principal - introduz-se o tema do dia, através da apresentação de imagens que representem bem o tema da sessão e pede-se ao grupo que tente adivinhar a temática; depois de apresentado o tema, a sessão continua com questões estimulantes sobre os vários elementos relacionados com o tema, que vão sendo apresentados, um de cada vez, ao grupo; sempre que é introduzido um novo elemento, pede-se ao grupo que o identifique e associe ao tema da sessão; à medida que vão sendo apresentados e experimentados (em alguns casos) os vários elementos, vai se pedindo que os participantes partilhem e relacionem as suas experiências, conhecimentos e memórias, enquanto o assunto é discutido.

(iii) fase final - resume-se a sessão, destacando-se os contributos pessoais e do grupo; reforça-se que a participação futura é essencial para o sucesso do grupo; agradece-se individualmente a participação; canta-se novamente a canção estabelecida no início e relembra-se a data, hora e tema da sessão seguinte. Despedidas.

Foram estabelecidos como princípios relevantes para os dinamizadores considerarem ao longo do desenvolvimento do programa, o permanecerem neutros e objetivos, sem fazerem juízos de valor, bem como o potenciarem a partilha de ideias e a implicação dos participantes na sugestão de futuros tópicos relacionados com o tema da sessão seguinte.

Os doze temas das sessões foram selecionados através de uma reunião com todos os alunos e docentes, que sugeriram temas em função do conhecimento prévio dos grupos que viriam a participar no programa, bem como dos pressupostos deste tipo de intervenção. Assim, o programa planeado e implementado foi constituído pelos temas e principais atividades descritos no quadro 1.

A estimulação multisensorial foi introduzida em todas as sessões. As pessoas eram convidadas a dar a sua opinião e a partilhar memórias de experiências e acontecimentos passados e não tanto o conhecimento factual acerca das temáticas exploradas. As atividades propostas possibilitavam que o dinamizador durante as sessões pudesse adaptar o nível de dificuldade da sessão às características (capacidades, dificuldades e interesses) dos vários participantes do grupo.

\section{Participantes}

Todas as fases de planeamento, desenvolvimento e avaliação do programa tiveram intervenção direta de 9 alunos da licenciatura em Educação Social, a realizar estágio curricular em instituições de apoio a pessoas idosas.
Quadro 1. Estrutura do programa de estimulação multisensorial e e reminiscencias

\begin{tabular}{|c|c|}
\hline $\begin{array}{l}\text { Tema da } \\
\text { sessão }\end{array}$ & Exemplo de atividades \\
\hline $\begin{array}{l}\mathbf{1}^{\mathrm{a}} \text { Local onde } \\
\text { se encontram }\end{array}$ & $\begin{array}{l}\text { Apresentação de elementos (ex.: imagens, } \\
\text { vídeos) identificadores do país, cidade, } \\
\text { freguesia e casa onde se encontram. }\end{array}$ \\
\hline $\begin{array}{l}2^{\mathrm{a}} \mathrm{Lo} \\
\text { nascel }\end{array}$ & $\begin{array}{l}\text { Apresentação de elementos identificadores } \\
\text { dos locais onde os participantes do grupo } \\
\text { nasceram, com recordação das experiências a } \\
\text { eles associadas. }\end{array}$ \\
\hline $\begin{array}{l}\mathbf{3}^{\mathbf{a}} \\
\text { Brincadeiras }\end{array}$ & $\begin{array}{l}\text { Apresentação de imagens de brincadeiras e } \\
\text { brinquedos antigos e debate sobre os } \\
\text { materiais, forma de utilização e recordações } \\
\text { associadas a esses brinquedos. }\end{array}$ \\
\hline $4^{a}$ Pro & $\begin{array}{l}\text { Partindo-se de fotografias e vídeos } \\
\text { ilustrativos de profissões atuais versus } \\
\text { antigas, estimulação do debate sobre as } \\
\text { principais diferenças entre o trabalho no } \\
\text { passado e no presente, enfatizando-se as } \\
\text { profissões dos participantes. }\end{array}$ \\
\hline $5^{\text {a } U t i l ~}$ & $\begin{array}{l}\text { Apresentação de utilitários através de } \\
\text { imagens e objetos, permitindo a } \\
\text { experimentação dos mesmos e discute-se a } \\
\text { sua utilização do presente e passado. }\end{array}$ \\
\hline $6^{\mathrm{a}} \mathrm{Oc}$ & $\begin{array}{l}\text { Apresentação de estímulos que representem } \\
\text { as atividades recreativas que os elementos do } \\
\text { grupo realizam e/ou realizavam, evocando } \\
\text { reminiscências associadas a esses momentos. }\end{array}$ \\
\hline $7^{\mathrm{a}} \mathrm{Cul}$ & $\begin{array}{l}\text { Confecção de uma receita que faça parte das } \\
\text { memórias dos elementos do grupo e } \\
\begin{array}{lllll}\text { estimulação sensorial a partir dos } \\
\text { ingredientes. }\end{array}\end{array}$ \\
\hline $\mathbf{8}^{\mathbf{a}} \mathrm{Agr}$ & $\begin{array}{l}\text { Simulação de uma atividade agrícola, } \\
\text { utilização de produtos hortícolas e frutícolas } \\
\text { para identificação e recordação do seu uso. }\end{array}$ \\
\hline $\mathbf{9}^{\mathbf{a}} \mathrm{Pa}$ & $\begin{array}{l}\text { Identificação de passeios realizados pelos } \\
\text { elementos do grupo com base em imagens e } \\
\text { vídeos e discussão sobre as experiências } \\
\text { positivas e negativas. }\end{array}$ \\
\hline $10^{\mathrm{a}} \mathrm{Ro}$ & $\begin{array}{l}\text { Apresentação de estímulos que evoquem } \\
\text { festas e romarias tradicionais. }\end{array}$ \\
\hline $11^{a} \mathrm{Re}$ & $\begin{array}{l}\text { Após a visualização e manuseamento de } \\
\text { imagens, objetos e sons associados à religião, } \\
\text { os participantes serão questionados sobre a } \\
\text { importância que a religião e espiritualidade } \\
\text { lhes transmite bem como possíveis histórias } \\
\text { pessoais e memórias relacionadas com o } \\
\text { tema. }\end{array}$ \\
\hline $\begin{array}{l}\mathbf{1 2}^{\mathbf{a}} \text { Estação } \\
\text { do ano }\end{array}$ & $\begin{array}{l}\text { Apresentação de elementos identificadores da } \\
\text { presente estação do ano e discussão de } \\
\text { memórias com ela relacionados. }\end{array}$ \\
\hline
\end{tabular}

Os destinatários do programa foram 16 pessoas idosas, com uma média de idades de 75,98 (DP = 12,97), 10 mulheres e 6 homens, 5 provenientes de uma estrutura residencial para pessoas idosas e 11 de centro de dia. Relativamente à escolaridade, 37,6\% dos participantes não frequentaram a escola, 43,8\% tem o ensino básico, $12,5 \%$ tem o ensino preparatório e 6,3\% o ensino superior.

\section{Instrumentos}

Non Pharmacological Therapy Experience Scale (NPT-ES, Muñiz et al., 2011) - é uma escala de 
observação do tipo ordinal (4 pontos) que avalia o comportamento dos sujeitos com base nos seguintes aspetos: participação, prazer, relação com os outros, desagrado e rejeição. Esta escala foi preenchida pelos dois dinamizadores do programa nas sessões 6 e 12, com base nos comportamentos, comunicação e linguagem não verbal de cada um dos participantes.

Focus group - após a implementação do programa desenvolveu-se uma discussão com os alunos que dinamizaram o programa e com os docentes que os acompanharam, de forma a conhecer a perceção dos dinamizadores das sessões acerca (i) do impacto e benefícios das sessões nos destinatários, (ii) das dificuldades e constrangimentos da implementação do programa, e (iii) da importância do seu envolvimento em todas as fases de planeamento, desenvolvimento e avaliação do programa para a formação de Educadores Sociais.

\section{Procedimento}

O planeamento do programa iniciou-se em novembro de 2014, com uma reunião de trabalho, em que os alunos e docentes definiram a estrutura do programa e de cada sessão, os temas, bem como o cronograma do programa de estimulação multissensorial e de reminiscências. Posteriormente, organizados em grupos de trabalhos, os alunos elaboraram o plano de cada sessão de acordo com os temas previamente definidos e construíram os respetivos materiais de apoio. A implementação do programa foi iniciada em janeiro de 2015, tendo sido realizada uma avaliação acerca dos comportamentos dos participantes no decorrer das sessões 6 e 12, com recurso ao NPT-ES. O programa foi desenvolvido numa estrutura residencial para pessoas idosas com uma periodicidade bissemanal e num centro de dia com uma periodicidade semanal. Em ambos, cada sessão contou com duas dinamizadoras. Após o términos da implementação, realizou-se uma reunião com os alunos e docentes, no sentido de avaliar as percepções dos alunos acerca do planeamento, desenvolvimento e avaliação do programa.

\section{Resultados}

A análise do comportamento dos participantes ao longo das sessões (6 e 12), avaliada através da NPT-ES, demonstrou que, em ambas, a maioria dos indivíduos participou frequentemente/sempre nas referidas sessões, procurando responder às questões que surgiram durante as mesmas e colaborando nas tarefas propostas (ver Tabela 1). Também ao nível do prazer os resultados foram satisfatórios, visto que nas sessões 6 e 12, grande parte dos participantes (81,3\% e $80,0 \%)$ mostrou-se interessado no decurso da sessão, como confirmado através dos comportamentos e comunicação não verbal (ex.: sorriso, gestos, postura, palavras ou ações). A relação com os outros também foi avaliada como positiva, estando relacionada com uma comunicação positiva, respeitosa e amigável para com os outros participantes da sessão. No entanto, é de notar que na sessão 12, um dos participantes (6,7\%) nunca se relacionou com os outros membros de grupo. Ao nível dos comportamentos reveladores de desagrado, embora se registasse na sessão 6 que dois participantes tinham demonstrado sentimentos negativos, o mesmo não se verificou na sessão 12, visto que nenhum dos participantes demonstrou sentimentos negativos, tais como mal-estar, ansiedade, tristeza, desconforto, vergonha e aborrecimento. Relativamente à rejeição, apesar da maioria dos participantes (81,3\% e 82,7\%) não ter demonstrado este tipo de comportamentos em ambas as sessões, verificou-se que na sessão 6, existiram participantes que a demonstraram algumas vezes (6,3\%) ou frequentemente $(12,5 \%)$, comportamentos estes que diminuíram de frequência na sessão $12 \quad(0,0 \%$ frequentemente e 13,3\% algumas vezes).

Tabela 1.

Comportamentos dos participantes nas Sessões 6 e 12

\begin{tabular}{llccccc}
\hline & & $\begin{array}{c}\mathrm{A} \\
(\%)\end{array}$ & $\begin{array}{c}\mathrm{B} \\
(\%)\end{array}$ & $\begin{array}{c}\mathrm{C} \\
(\%)\end{array}$ & $\begin{array}{c}\mathrm{D} \\
(\%)\end{array}$ & $\begin{array}{c}\mathrm{E} \\
(\%)\end{array}$ \\
\hline Nunca & S 6 & 0,0 & 0,0 & 0,0 & 87,5 & 81,3 \\
& S 12 & 0,0 & 0,0 & 6,7 & 100 & 86,7 \\
Algumas & S 6 & 25,0 & 18,8 & 18,8 & 6,3 & 6,3 \\
vezes & S 12 & 13,3 & 20,2 & 13,3 & 0,0 & 13,3 \\
Frequente/ & S 6 & 25,0 & 31,3 & 25,5 & 6,3 & 12,5 \\
& S 12 & 46,7 & 46,7 & 40,0 & 0,0 & 0,0 \\
Sempre & S 6 & 50,0 & 50,0 & 56,3 & 0,0 & 0,0 \\
& S 12 & 40,0 & 33,3 & 40,0 & 0,0 & 0,0 \\
\hline
\end{tabular}

Legenda: A - Participação; B - Prazer; C - Relação com os outros; D Desagrado; E - Rejeição

O desenvolvimento do focus group após a implementação do programa possibilitou recolher e analisar informações de relevo acerca da perpeção dos alunos sobre o impacto do programa. No que se refere ao impacto e benefícios das sessões nos destinatários, é de destacar:

- os participantes foram muito interventivos e inclusive, em algumas sessões, foi difícil efetuar o encerramento pelo facto de estarem muito entusiasmados e não quererem terminar a atividade;

- o formato da sessão foi considerado uma mais-valia, pois ao ser iniciada e terminada com questões sobre o tempo (ex.: dia da semana, dia do mês), possibilitou que os participantes ao longo das sessões fossem apresentando maior capacidade de orientação temporal;

- as atividades de estimulação multissensorial permitiram identificar dificuldades sensoriais em alguns dos participantes, que ainda não tinham sido identificadas pelos profissionais da instituição (ex.: défice olfativo);

- a intervenção grupal permitiu que se gerasse maior motivação, visto que uns participantes estimulavam os outros;

- a sessão sobre culinária permitiu uma maior estimulação e envolvimento dos participantes, pelo que foi considerada pelos dinamizadores como a mais eficaz. 
Ao nível das dificuldades e constrangimentos da implementação, os alunos referiram:

- que alguns participantes revelaram ansiedade inicial por receio de não conseguirem cumprir os objetivos da sessão;

- que se verificaram maiores dificuldades no programa que foi desenvolvido semanalmente comparativamente ao bissemanal devido ao maior espaçamento temporal entre sessões.

Relativamente ao parâmetro da importância do envolvimento dos alunos em todas as fases de planeamento, desenvolvimento e avaliação do programa para a formação de Educadores Sociais, e comparando este programa com outras atividades não estruturadas desenvolvidas no âmbito do estágio, os alunos destacam:

- que houve maior interesse dos próprios pelo programa, pelo facto de se tratar de uma intervenção estruturada, em que eles participaram desde o início na sua construção e definição, com o apoio de docentes, o que contribuiu para que se sentissem mais seguros na intervenção;

- que houve um maior reconhecimento por parte dos familiares e dos técnicos, que ao terem oportunidade de observar algumas sessões destacaram a originalidade do programa, a escolha das temáticas e a sua importância face aos problemas dos clientes.

\section{Discussão}

Tendo em conta que as pessoas idosas constituem o grupo em maior crescimento no nosso país, é fundamental desenvolver um conhecimento mais aprofundado ao nível das práticas de intervenção com esta população. O Educador Social surge como um profissional de destaque na intervenção socioeducativa com pessoas idosas, contribuindo para a concretização dos princípios subjacentes ao envelhecimento bem sucedido, nomeadamente através da dinamização de atividades de estimulação (Araújo et al., 2014).

Aquando a formação inicial de Educadores Sociais é importante que as instituições formadoras invistam no desenvolvimento das suas competências práticas de elaboração e gestão de projetos, implicando-os na construção, implementação e avaliação de instrumentos de intervenção adequados às populações-alvo (Serrano, 2014).

Dados recolhidos no presente estudo sublinharam a importância de existir um programa estruturado de intervenção, comparativamente à dinamização de atividades pontuais que tendem a ser desenvolvidas nos contextos de intervenção com pessoas idosas. O envolvimento dos alunos em todas as etapas de desenvolvimento do programa revelou-se fundamental para a sua motivação e desenvolvimento de competências de intervenção e avaliação crítica, considerando-se como uma mais-valia para o seu perfil profissional.

\section{Referências}

Afonso, R.M. (2012). Reminiscência Como Técnica de Intervenção Psicológica em Pessoas Idosas. Lisboa: Gulbenkian.

Araújo, L., Amante, M.J., Fonseca, S., Xavier, P., Martins, E., Mendes, F., Fernandes, R., \& Magalhães, C. (2014). A prática do educador social no envelhecimento: da formação à ação. In P. Delgado et al. (Coords.), Pedagogia/Educação Social - Teorias e Práticas: Espaços de Investigação, Formação e Ação (pp.24-28). Porto: Escola Superior de Educação do Porto. ISBN: 978-972-8969-06-6.

Baillon, S., van Diepen, E., \& Prettyman, R. (2002). Multi-sensory therapy in psychiatric care. Advances in Psychiatric Treatment, 8, 444-450.

Bohlmeijer, E. T., Roemer, M., Cuijpers, P., \& Smit, F. (2007). The effects of life-review on psychological well-being in older adults: a meta-analysis. Aging and Mental Health, 11, 291-300.

Muñiz, R. Olazarán, J., Poveda, S., Lago, P., \& Peña-Casanova, J. (2011). NPT-ES: A measure of the experience of people with dementia during non-pharmacological interventions. Non-Pharmacological Therapies in Dementia, 1, 1-11.

Paúl, C., \& Ribeiro, O. (2012). Manual de Gerontologia. Lisboa: LIDEL.

Serrano, G. (2014). Elaboração de Projetos Sociais. Porto: Porto Editora.

Victorian Government (2010). Sensory stimulation. Disponível em: www.health.vic.gov.au/dementia

Willemse, B., Depla, M., \& Bohlmeijer, E. (2009). A creative reminiscence program for older adults with severe mental disorders: Results of a pilot evaluation. Aging \& Mental Health, 13, 736-743.

\section{Agradecimentos}

Agradecemos ao CI\&DETS, IPV, bem como aos estagiários do curso de Licenciatura em Educação Social, da Escola Superior de Educação de Viseu, que participaram no desenvolvimento do programa, bem como às pessoas idosas que participaram no mesmo.. 